\title{
Causas de dificuldades no Ensino-Aprendizagem de Cálculo diferencial e integral na perspectiva dos alunos e dos professores do curso de matemática da UFAL - Campus de Arapiraca
}

\author{
Thainnã T. Oliveira Sena Ademária A. de Souza \\ Universidade Federal de Alagoas - Eixo da Educação - Matemática Licenciatura \\ 57309-005, Campus de Arapiraca, Arapiraca, AL \\ E-mail: thainna_sena@hotmail.com_E-mail: ademariasouza@yahoo.com.br
}

\section{RESUMO}

O Cálculo Diferencial e Integral (CDI) é uma das principais ferramentas matemática tendo diversas aplicações científicas e tecnológicas em quase todos os campos das ciências pura e aplicada. Apesar de tantas possibilidades, as dificuldades no processo ensino-aprendizagem do Cálculo têm sido foco de diversas pesquisas nacionais e internacionais, por ser alvo de alto índice de reprovação, evasão e trancamento.

No que diz respeito à Universidade Federal de Alagoas (UFAL) - Campus de Arapiraca, o panorama não difere do fenômeno ocorrente em outras instituições de ensino superior que contêm a disciplina de Cálculo. De acordo com os dados fornecidos pela coordenação do curso de Matemática nos períodos de 2010.1 a 2012.1 o percentual de desistência (trancamento) e de reprovação dos alunos que se matricularam na disciplina de CDI é em média de 52\%, sendo um rendimento e desempenho muito baixos e altamente preocupantes.

Tendo em vista o alto índice de reprovação na disciplina citada oferecida no curso de Matemática Licenciatura, na Universidade Federal de Alagoas - Campus de Arapiraca, o objetivo deste trabalho é investigar os possíveis obstáculos que influenciam no alto índice de reprovação na disciplina de Cálculo Diferencial e Integral visando fornecer subsídios para minimizar o problema da evasão e repetência na referida disciplina.

A pesquisa foi realizada em dois momentos. No primeiro momento procurou-se investigar quais obstáculos contribuem, na visão dos alunos, para esse alto índice de repetência. Para isso, foi realizada uma pesquisa tipo censo com os licenciandos em matemática devidamente matriculados na disciplina Cálculo Diferencial e Integral na Universidade Federal de Alagoas (UFAL) Campus de Arapiraca entre os dias 09 e 11 de maio de 2013, para a coleta de dados dos alunos foi utilizado um questionário predominantemente estruturado de 25 questões. Em um segundo momento, foi realizada uma pesquisa entre os dias 15 e 17 de maio de 2013, com todos os professores do curso de Matemática que lecionaram e/ou lecionam a disciplina de Cálculo Diferencial e Integral no período de 2010.1 a 2012.2 na instituição pesquisada, pesquisando um total de 6 professores procurando identificar, na visão dos professores, prováveis fatores do fracasso na aprendizagem escolar. O levantamento de dados dos professores também foi realizado por meio de um questionário semi estruturado com 17 questões. De posse dos questionários respondidos pelos entrevistados, os dados foram analisados por meio de técnicas estatísticas de análise exploratória.

Os dados levantados pelos questionários aplicados aos alunos e aos professores evidenciam que os principais fatores contribuintes para o elevado índice de reprovação dos licenciandos da disciplina de Cálculo dizem respeito a vários aspectos relacionados tanto aos alunos quanto aos professores e à instituição.

Os principais aspectos relacionados aos discentes são: pouco tempo dedicado ao estudo da disciplina fora da sala de aula, participação limitada nas aulas, falta de hábito constante de realizar consultas a outras fontes de estudo, não procura o professor para esclarecer dúvidas, desinteresse e a falta de esforço para aprender o conteúdo da matéria, deficiência de conhecimentos básicos de matemática, se preocupa apenas em obter créditos desta disciplina e não em aprendê-la.

Embora na visão dos alunos os professores apresentem domínio do conteúdo, cita-se como aspectos relacionados aos docentes: metodologia do professor utilizada em sala de aula e 
rigorosidade nos critérios de avaliação (aplicação e correção), a maioria não relaciona os conteúdos da disciplina com outras áreas do conhecimento. De acordo com [3] as causas que contribuem para o alto índice de repetência em Cálculo são várias e já bem conhecidas, principalmente no que diz a respeito à má formação adquirida durante o $1^{\circ}$ e $2^{\circ}$ graus, em que grande parte dos alunos chega à universidade sem domínio de conceitos básicos, com pouca capacidade crítica, sem hábitos de estudar e bastante inseguros.

De acordo com a opinião dos alunos, a forma que aprendem mais o Cálculo em sala são as aulas expositivas tradicionais (30\%) seguidas das aulas dialogadas (29\%), trabalhos em grupo (18\%), aulas práticas $(15 \%)$ e em atividades de pesquisa (8\%). Esses resultados corroboram com os obtidos por [2], em que as aulas tradicionais meramente expositivas, são preferidas pela maioria, possivelmente pela posição que se encontra o aluno, em relação à crença: "o professor ensina mostrando e o aluno aprende vendo", ou seja, o professor é o sujeito do suposto saber.

Acredita-se que tais questões devem ser objeto de reflexão por parte de todos os "atores" dos processos de ensino e de aprendizagem de Cálculo: os professores devem refletir / repensar no papel do Cálculo na formação matemática dos alunos; e alunos, que devem refletir/ reconhecer a importância da construção dos conceitos do Cálculo para sua formação matemática e profissional [1].

Salienta-se ainda, que tanto os docentes quanto os discentes assumem uma parcela de culpa dos problemas abordados no presente trabalho, os docentes assumem que alguns itens que contribuem para a reprovação dos acadêmicos na disciplina de Cálculo são fatores referentes à sua própria atuação com o alunado e fatores referentes ao corpo docente e, os alunos na maioria das vezes atribuem fatores existentes à sua conduta. É relevante o reconhecimento de ambas as partes e um bom começo para mudanças em sua forma de agir no ambiente acadêmico. Sob essa perspectiva, o processo de construção de conhecimentos da referida disciplina deve ser uma ação conjunta entre alunos, professores e instituição.

Palavras-chave: Aprendizagem, reprovação, alternativas de ensino, obstáculos na aprendizagem.

\section{Referências}

[1] O. H. Abreu, "Discutindo algumas relações possíveis entre intuição e rigor entre imagem conceitual e definição conceitual de ensino de limites e continuidade em cálculo I", Dissertação de Mestrado, Universidade Federal de Ouro Preto, Ouro Preto, 2011.

[2] M. A. Barbosa, "O insucesso no ensino e aprendizagem na disciplina de cálculo diferencial e integral", Dissertação de Mestrado, Pontifícia Universidade Católica do Paraná - PUCPR Curitiba, 2004.

[3] A. Barreto, O ensino do cálculo I nas universidades. Informativo da Sociedade Brasileira de Matemática, SBM, n.6, pp. 4-5, (1995). 